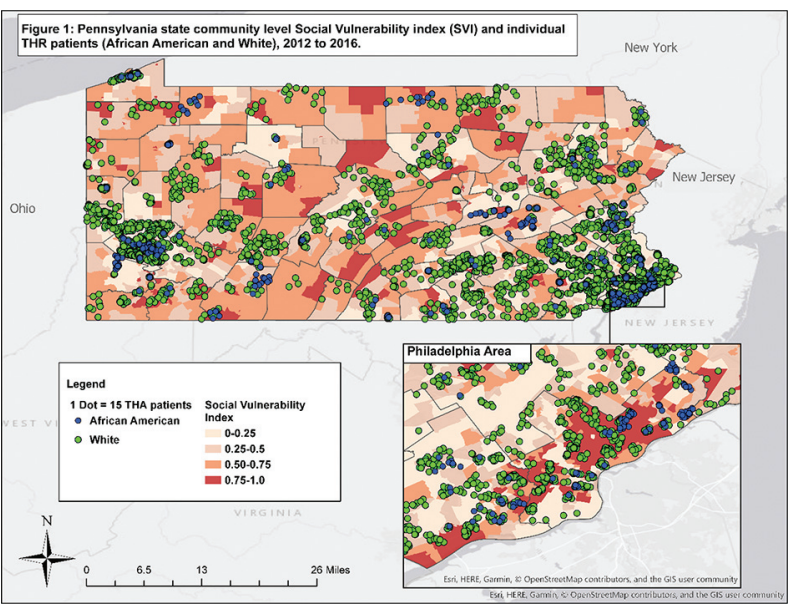

Abstract THU0442 - Figure 1. Pennsylvania state community level Social Vulnerability index (SVI) and individual Total Hip Replacement patients (African American and White), 2012 to 2016

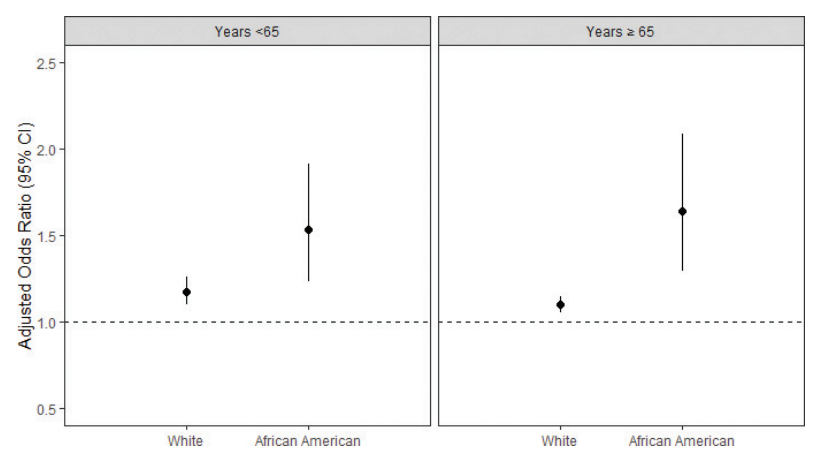

Abstract THU0442 - Figure 2. Adjusted odds of discharge to an Institution (vs Home) for patients living in High SVI compared to Low SVI stratified by race

${ }^{a}$ Adjusted covariates for all models include patient sex, age, insurance, facility metro status, volume of cases, surgical complications, and Elixhauser Index.

Disclosure of Interests: Bella Mehta: None declared, Susan Goodman Grant/research support from: Novartis: research support, Consultant for: Novartis, UCB, Pfizer: consulting, Kaylee Ho: None declared, Debra D'Angelo: None declared, Michael Parks Grant/research support from: Zimmer Biomet, Employee of: Zimmer Biomet, Said Ibrahim: None declared DOI: 10.1136/annrheumdis-2019-eular.6114

\section{THU0443 ASSESSING PAIN CHARACTERISTICS IN PERSONS WITH HAND OSTEOARTHRITIS USING THE MCGILL PAIN QUESTIONNAIRE}

Elisabeth Mulrooney ${ }^{1}$, Karin Magnusson ${ }^{2,3}$, Hilde Berner Hammer ${ }^{1}$, Hanne Solveig Dagfinrud ${ }^{2,4}$, Tore K. Kvien ${ }^{1,5}$, Ida Kristin Haugen ${ }^{1} .{ }^{1}$ Diakonhjemmet Hospital, Department of Rheumatology, Oslo, Norway, ${ }^{2}$ Diakonhjemmet Hospital, National Advisory Unit on Rehabilitation in Rheumatology, Oslo, Norway; ${ }^{3}$ Lund University, Department of Orthopedics, Lund, Sweden; ${ }^{4}$ University of Oslo, Department of Interdiciplinary Health Sciences, Oslo, Norway; ${ }^{5}$ University of Oslo, Department of Orthopaedics, Oslo, Norway

Background: Pain in osteoarthritis (OA) causes significant physical, psychological and social limitations. Increased understanding of the pain experience is important for improved patient care.

Objectives: We aimed to assess the pain characteristics of hand OA using the McGill Pain Questionnaire, a multidimensional self-reporting questionnaire that assesses the quality and intensity of the pain. Secondly, the external validity was examined.

Methods: Three-hundred persons with hand OA from the Nor-Hand study completed questionnaires, including a modified McGill questionnaire. The participants are presented with a list of 106 pain descriptors in 18 sections. The questionnaire consists of three subscales: sensory (12 sections, $0-71.3$ scale), affective ( 5 sections, 0-32.9 scale) and evaluative (one section, 0-8.6 scale), and an intensity score (no pain - severe pain). The total scale is rated from $0-112.8$. The subscales and total scale were normalized to $0-100$ scales. The participants also completed the Numeric Rating Scale (NRS, 0-10 scale) about hand pain, the Australian/ Canadian (AUSCAN) hand pain subscale (0-20 scale) and questionnaires about psychological factors; Hospital Depression and Anxiety Scale (HADS, 0-42 scale), Pain Catastrophizing Scale (PCS, 0-52 scale) and the pain subscale of the Arthritis Self Efficacy Scale (ASES, 10-100 scale). For all scales except ASES, high scores indicate poor health. We identified the adjectives in the McGill questionnaire with most frequent responses. To determine the external validity, the McGill questionnaire was correlated to other questionnaires (AUSCAN, NRS, HADS, PCS and ASES) using Spearman correlation coefficients.

Results: The participants ( $89 \%$ women) with median (IQR) age of 61 (57-66) years demonstrated a wide range in pain characteristics and intensity, with a median (IQR) of 34.5 (0-62.3), 14.9 (0-39.2) and 44.2 (34.9-48.8) for the sensory, affective and evaluate subscales, respectively. The median for the total pain sum score was 29.7 (7.0-53.2). A floor effect was detected for the sensory $(23.7 \%$ with score 0$)$ and affective $(40.3 \%$ with score 0$)$ subscales. The reported adjectives with highest frequency were "sore" ( $n=208,69.3 \%)$, "inhibiting" ( $n=124,41.3 \%)$ and "annoying" ( $n=97,32.3 \%)$. The participants frequently reported neuropathiclike characteristics such as sticking/stabbing/pricking $(n=137,45.7 \%)$, speeding/radiant $(n=110,36,6 \%), \quad$ smarting/burning $(n=89,29.6 \%)$ and creeping ( $n=43,14.3 \%)$.

The McGill total scale showed moderate correlations with AUSCAN and NRS pain (Table). Similar strength of correlations was found for all the subscales, and stronger for the intensity score (0.63-0.64). The correlation with HADS was similar for the McGill questionnaire, AUSCAN and NRS pain. The correlations with PCS and ASES were weaker for McGill than for the other pain questionnaires.

Abstract THU0443 -Table 1. Correlations between the McGill questionnaire and questionnaires assessing pain and psychological health.

\begin{tabular}{lcccccc}
\hline & $\begin{array}{c}\text { McGill } \\
\text { total }\end{array}$ & AUSCAN & $\begin{array}{c}\text { NRS } \\
\text { pain }\end{array}$ & HADS & PCS & ASES \\
\hline McGill & 1.0 & & & & & \\
total & & 1.0 & & & & \\
AUSCAN & 0.41 & 0.73 & 1.0 & & & \\
NRS pain & 0.45 & 0.24 & 0.29 & 1.0 & & \\
HADS & 0.31 & 0.40 & 0.41 & 0.47 & 1.0 & \\
PCS & 0.26 & -0.35 & -0.40 & -0.30 & -0.42 & 1.0 \\
ASES & -0.20 & & & & & \\
\hline
\end{tabular}

Conclusion: The McGill Pain questionnaire may be a useful tool in research settings for a broad evaluation of pain characteristics in hand OA. Moderate correlations with other pain questionnaires suggest that the McGill questionnaire measures other constructs. For the first time, we have shown that neuropathic-like pain characteristics are frequently reported by persons with hand OA.

Disclosure of Interests: Elisabeth Mulrooney: None declared, Karin Magnusson: None declared, Hilde Berner Hammer Grant/research support from: AbbVie, Pfizer and Roche, Paid instructor for: AbbVie, Pfizer, UCB, Novartis, Roche, Speakers bureau: AbbVie, Pfizer, UCB, Novartis, Roche, Hanne Solveig Dagfinrud Consultant for: Honoraria from Novartis as a steering committee member on this survey, Tore K. Kvien Grant/research support from: AbbVie, BMS, MSD, Pfizer, Roche and UCB., Consultant for: AbbVie, Biogen, BMS, Boehringer Ingelheim, Celgene, Celltrion, El Lilly, Hospira, Merck-Serono, MSD, Novartis, Oktal, Orion Pharma, Pfizer, Roche, Sandoz, Sanofi, Mylan and UCB, Speakers bureau: AbbVie, Biogen, BMS, Boehringer Ingelheim, Celgene, Celltrion, Eli Lilly, Hospira, Merck-Serono, MSD, Novartis, Oktal, Orion Pharma, Pfizer, Roche, Sandoz, Sanofi and UCB, Ida Kristin Haugen Grant/research support from: ADVANCE research grant from Pfizer, Consultant for: Advisory board Abbvie

DOI: 10.1136/annrheumdis-2019-eular.4606

\section{THU0444 CROSS-CULTURAL TRANSLATION, ADAPTATION AND VALIDATION OF A JAPANESE VERSION OF THE FUNCTIONAL INDEX FOR HAND OSTEOARTHRITIS (J- FIHOA)}

Yasunobu Nakagawa ${ }^{1}$, Shigeru Kurimoto ${ }^{1}$, Emmanuel Maheu ${ }^{2}$, Renée Liliane Dreiser ${ }^{3}$, Hitoshi Hirata $1 .{ }^{1}$ Nagoya University Hospital, Hand Surgery, Nagoya, Japan; ${ }^{2}$ Hôpital Saint-Antoine, APHP, Rheumatology, Paris, France; ${ }^{3}$ Hopital Bichât, APHP, Rheumatology, Paris, France

Background: Hand osteoarthritis (HOA) is a highly prevalent and heterogeneous musculoskeletal disorder. Although well-designed clinical trials and guidelines have been published, there are comparatively few HOA 